\title{
BMMB: past and future
}

\section{J. D. Humphrey}

Published online: 3 May 2011

(C) Springer-Verlag 2011

It is my great pleasure to introduce Dr. Larry A. Taber as the new co-Editor in Chief of Biomechanics and Modeling in Mechanobiology (BMMB). Dr. Taber is the Dennis and Barbara Kessler Professor of Biomedical Engineering at Washington University in St. Louis. A respected scholar and educator, Dr. Taber has contributed to the advancement of many areas within biomechanics and has been a pioneer in the growing area of Developmental Biomechanics. We are very fortunate that Dr. Taber has agreed to serve with Dr. Holzapfel as BMMB enters its second decade. Indeed, Dr. Taber has been a strong supporter of BMMB since its establishment; he contributed an excellent paper to the first issue, published in 2002, and he has been one of the most willing and active referees over the years.

It is hard for me to believe that it has been 10 years since we established BMMB, but I could not be more proud of what has been accomplished during this period. BMMB is now recognized as a leading journal in the fields of biomechanics, mechanobiology, and biomechanical modeling, which is reflected in part by the latest ISI impact factor of 3.169-the highest in biomechanics and among the top ten in biomedical engineering. I thus think it appropriate as we look forward to the next decade to reflect briefly on the past decade, which brought us to this point.

Dr. Holzapfel conceived the idea of a new journal in biomechanics in 1999. Following early discussions with a possible publisher, he then contacted me to discuss this opportunity. We decided that it would be important to establish a journal that promoted the allied fields of biomechanics and modeling in mechanobiology and then approached Springer early in 2000 as a possible publisher. Suffice it to say that we were extremely impressed with everyone we talked to at Springer, one of the world's leading publishers of advances in science and engineering. Hence, Dr. Holzapfel and I signed contracts with Springer on November 28, 2000 to establish
BMMB. Indeed, among the many at Springer who have contributed so much to the success of BMMB, I would especially like to thank publically Erdmuthe Raufelder, Journals Coordinator in Physical Sciences and Engineering at Springer, and Dr. Dieter Merkle, Editorial Director of Engineering at Springer. Both have been wonderful partners in ensuring the success of BMMB, and I am very grateful to have been able to get to know them personally and to have been able to work with them.

On December 19, 2000, we invited twelve international experts in biomechanics and computational mechanics to constitute the initial Editorial Board, six from the USA and six from Japan, Europe, and New Zealand. Although asked to serve an initial three-year term, they each have served the journal well during this first decade. They are G. Athesian, S. Cowin, T. Hughes, R. Kamm, G. SchmidSchonbein, and R. Spilker from the USA and K. Hayashi, P. Hunter, R. Ogden, T. Pedley, A. Rachev, and P. Wriggers. Having established the editorial board, aims, and scope, Dr. Holzapfel and I sent 75 letters during June 2001 to leaders in the field to request submissions; the first paper was received in September 2001. We also wanted to establish a reputation of rigor from the very beginning, and of the initial 18 submissions, 9 were accepted and 9 were rejected.

The first issue appeared in June 2002, which included a thoughtful and challenging forward by Professor Y.C. Fung who supported our efforts fully. Things began to move quickly thereafter. With support from many leaders in the field, including Professors F. Guilak, Editor of Journal of Biomechanics, and F. Yin, Editor of Journal of Biomechanical Engineering, BMMB was approved by the US National Library of Medicine within the shortest period possible to be indexed via PubMed / Medline. After the requisite waiting period, BMMB received its first impact factor (2.604) in 
2007, which placed it second in the field biomechanics- $\mathrm{a}$ very good start.

Obviously, the great success enjoyed by BMMB is due to many people, whom I wish to thank. They are the many authors who trusted us by sending their excellent work for consideration for publication, the many reviewers who ensured that the level of scholarship remained very high, the production and support team at Springer who have been wonderful, and our excellent editorial board. In closing, however, I would especially like to thank Dr. Holzapfel for his initial vision, but more importantly for being a wonderful collaborator throughout this past decade. It truly has been a great pleasure working together over this past decade. I thus wish Drs. Holzapfel and Taber and BMMB the very best as we begin our second decade. 